\title{
sensors
}

ISSN 1424-8220

(C)2003 by MDPI

http://www.mdpi.net/sensors

\section{The Electrochemical Detremination of Nitric Oxide in Seawater Media with Microelectrodes}

\author{
Zhengbin Zhang ${ }^{1,2 *}$, Lei Xing ${ }^{1}$, Liqing Jiang ${ }^{2}$, Yongchen Wang ${ }^{2}$, Chunyan Ren ${ }^{1}$ and Wei-Jun \\ $\mathrm{Cai}^{2 * *}$ \\ ${ }^{1}$ Institute of Marine Chemistry, Ocean University of China, Qingdao 266003, China, \\ e-mail: zhangzb@mail.ouc.edu.cn; Fax: +86-532-2032483 \\ ${ }^{2}$ Department of Marine Science, the University of Georgia, Athens, GA 30602, USA \\ **wcai@arches.uga.edu; Tel: 706-542-1285 \\ * Authors to whom correspondence should be addressed.
}

Received: 15 April 2003 / Accepted: 02 May 2003 / Published: 22 August 2003

\begin{abstract}
The electrochemical determination of nitric oxide in seawater with microelectrodes is reported in this paper. Two electrodes, ISO-NOPMC microsensor and modified platinum microelectrode, are evaluated for their performance in seawater. The peak current is found to be linear with the NO concentration in the range $1 \times 10^{-6}-1.2 \times 10^{-5}$ $\mathrm{mol} / \mathrm{l}$ for both microelectrodes. The detection limit of ISO-NOPMC microsensor is $1.4 \times 10^{-8}$ mol/l. Two methods for calibration of NO sensor, saturated NO solutions and decomposition of S-nitroso-acetyl-DL-penicillamine (SNAP), are discussed and compared. In addition, we examined the performance degradation of these microelectrodes in seawater due to complexation with seawater components.
\end{abstract}

Keywords: ISO-NOPMC microsensor, modified platinum microelectrode, Nitric oxide, Seawater, SNAP

\section{Introduction}

Glonoin was applied to treat cardiopathy, which is a compound to relax blood vessel. In 1977, Murad discovered the glonoin released nitric oxide (NO) that causes vasodilation of smooth muscles. It was reported that endothelial cells could produce an relaxation factor-EDRF(endothelium-derived relaxing factor) which caused vasodilation of smooth muscles and the EDRF was NO [1-4]. In 1992, 
NO was appraised as "the molecule of the year" [5]. In 1998, Furchgott, Ignarro and Murad were awarded the Nobel prize for their research of NO in biological system. NO, a traditional physiological toxin, becomes important relaxation factor in various physiological processes. It is attracting more and more attention in many fields, including ocean biogeochemistry [6].

Archer[7] has summarized various NO detection methods, most of which involve indirect detection of the NO oxidation products. Direct methods have also been reported, including spectroscopic methods (e.g., chemiluminescence) and electrochemical methods[8-13]. Among these techniques, electrochemical methods are the most advantageous because they are simple, relatively fast, sensitive, in situ and direct.

Modified microelectrode probes are based on the catalytic reduction or oxidation of NO and are generally modified by three kinds of compound: (1) transitional metal-porphyrin (e.g., Ni (II) porphyrin )[14-15]; (2) metal-phthalocyanine (e.g., Co(TAPC))[16]; (3) metal-schiff base (e.g., $\mathrm{Co}($ salen))[17-18]. In this paper, home made (Nafion+Co(salen)) modified platinum microelectrode and ISO-NOPMC microsensor[19,20] produced by Word Precision Instrument (USA) are used. It is reported that the lower detection limit of ISO-NOPMC is around $0.3 \mathrm{nM}$, the current is linear when 1 $\mathrm{nM}<[\mathrm{NO}]<10 \mathrm{ì} \mathrm{M}$, and the response time less than $5 \mathrm{~s}$. The detection of NO in PBS buffer solution $\left(8.0 \mathrm{~g} \mathrm{NaCl}+2.9 \mathrm{~g} \mathrm{Na}_{2} \mathrm{HPO}_{4}+0.2 \mathrm{~g} \mathrm{KCl}+0.2 \mathrm{~g} \mathrm{KH}_{2} \mathrm{PO}_{4}+0.1 \mathrm{~g} \mathrm{MgCl}_{2} \cdot 6 \mathrm{H}_{2} \mathrm{O}\right.$ dissolved in $1 \mathrm{~L}$ aqueous solution, $\mathrm{pH}$ 7.4) has been reported in biological and physiological fields[1-7, 13-21, 27]. However, up to now, there is no report concerning direct measure of NO in seawater media. The aim of this work is to assess the applicability of (Nafion+Co(salen)) modified platinum microelectrode and ISO-NOPMC microsensor for the measurement of NO in seawater.

\section{Experimental}

\section{Chemicals}

Pure NO gas (99.5\%, National, USA), pure nitrogen gas(99.999\%, BOC Gas, USA); CuCl, $\mathrm{CuCl}_{2} \cdot 2 \mathrm{H}_{2} \mathrm{O}$, EDTA, HPLC grade water were obtained from Sigma-Aldrich (St. Louis, USA). SNitroso-N-acetyl-DL-penicillamine ( SNAP, purity>97\%) was received from World Precision Instruments (Sarasota, USA); Nafion-117) 5\% aqueous-alcoholic solution, Aldrich), Co(Salen) ( AlFa), Natural seawater (from nearshore of Qingdao, China and Georgia, USA) filtered by 45i $\mathrm{m}$ membrane filter. All other products were of analytical grade and used as received.

NO standards were prepared by making serial dilutions of saturated NO solutions: HPLC grade water $(2 \mathrm{ml})$ was bubbled with nitrogen for $30 \mathrm{~min}$ to remove oxygen. Then the solution was bubbled with pure NO gas for 30 minutes. The concentration of a saturated NO solution is $1.4 \mathrm{mM}$ [21-22]. Standards were freshly made for each experiment and kept in a glass flask with a rubber septum. Dilutions of the saturated solution were made using deoxygenated HPLC grade water.[21]

Standard stock SNAP solution[19,27]: $500 \mathrm{ml}$ of HPLC grade water was adjusted to $\mathrm{pH}$ 9.0; before dissolving $7 \mathrm{mg}$ of EDTA; deoxygenated with pure nitrogen for $20 \mathrm{~min}$. $11.0 \mathrm{mg}$ SNAP was finally added to the mixture and the resultant solution refrigerated in the dark (light-sensitive, slowly decomposes at room temperature). Solutions were freshly prepared for each experiment. 
$\mathrm{CuCl}$ saturated solution: $150 \mathrm{mg} \mathrm{CuCl}$ was added to $500 \mathrm{~mL}$ deoxygenated distillated water and kept in dark. The $\mathrm{pH}$ of the solution was adjusted with $0.01 \mathrm{M} \mathrm{HCl}$ or $0.01 \mathrm{M} \mathrm{NaOH}$. The concentration of a saturated $\mathrm{CuCl}$ solution is approximately $2.4 \mathrm{mM}$ at room temperature[26].

\section{Electrochemical instrumentation}

Electrochemical experiments were performed on a Model-630 Electrochemical Analyzer (HCH Instruments, USA) connected with an ISO-NOPMC microsensor[28] and on a HY-1CZ polarograph (JIPU Instruments, Qingdao, China) connected with a modified platinum microelectrode, an $\mathrm{Ag} / \mathrm{AgCl}$ reference electrode and a platinum wire auxiliary electrode.

\section{Electrode preparation}

ISO-NOPMC microsensor: Allow the sensor to polarize for at least one hour in $0.1 \mathrm{M} \mathrm{CuCl}_{2}$ before use. During polarization the backgroud current of the sensor, observed as the base line on a currenttime chart, will decrease slowly. The sensor is ready to use when the background current has reached a stable value (after approximately 1 hour). The background current should be approximately zero.

Modified platinum microelectrode: The modified platinum microelectrode was a platinum microdisk. The platinum microdisk was home-made by using a platinum wire of $0.5 \mathrm{~mm}$ diameter sealed in soft glass capillaries. The end section of the microdisk electrode was polished and carefully rinsed with distilled water and ethanol. Then platinum microelectrode was coated with $\mathrm{Co}(\mathrm{salen})$ and Nafion (2:1). After air drying, the sensor is ready to use.

\section{Two methods for calibration of $\mathrm{NO}$ sensor}

Calibration of NO microsensor is a key step to measurements of NO. Currently there are three methods[19] to calibrate electrochemical NO microsensor: (1) chemical generation of NO from the reaction of iodide with nitrite in acid solution, but the microsensor will be eroded and damaged in acid solution; (2) preparation of aqueous solutions of NO standards from saturated NO solutions, but the method takes time and has stronger toxicity, and the concentration of NO saturated solution has two values in literature (1.4 $\mathrm{mM}[21]$ and $2 \mathrm{mM}[23])$; (3) decomposition of S-nitroso-acetyl-DLpenicillamine (SNAP) to release of $\mathrm{NO}$ in the presence of $\mathrm{Cu}^{+}[19,27]$, but the method need more data to be quantified[25]. In this paper, methods (2) and (3) for ISO-NOPMC microsensor were used and compared.

\section{Electrochemical measurement of $N O$}

$10 \mathrm{ml}$ deoxygenated filtered natural seawater was placed in the electrochemical cell and aliquots of standard, saturated or diluted, NO solution were added with gas-tight syringe. Electrochemical responses of the modified platinum microelectrode to $\mathrm{NO}$ were evaluated by scanning from $0.2 \mathrm{v}$ to 1 $\mathrm{v}$ at a $200 \mathrm{mv} / \mathrm{s}$ on the HY-1CZ polarograph. Electrochemical responses of ISO-NOPMC microsensor to NO were evaluated by current-time plot on Model-630 Electrochemical Analyzer. During the 
measurement, the electrochemical cell was sealed and kept under nitrogen gas. During measurements, the solution was stirred.

The ISO-NOPMC microsensor was immersed into $10.0 \mathrm{~mL}$ of the deoxygenated filtered natural seawater. Known volumes of the standard SNAP solution and $\mathrm{CuCl}$ were then injected into the seawater solution, and the responses were minitored and recorded on Model-630 Electrochemical Analyzer. During measurements, the solution was stirred.

\section{Results and Discussion}

The lower detection limit and linear range of ISO-NOPMC sensor in seawater

Fig.1 shows a "stair-type" current-time curve of the ISO-NOPMC microsensor to the successive additions of $1.4 \mu \mathrm{M}$ NO in seawater. The relation between the measured current and the NO concentration is linear for NO concentrations ranging from $1 \mu \mathrm{M}$ to $10 \mu \mathrm{M}$. The result is similar to the literature [19,20], but the value is 10 times that of the literature (Fig. 2).

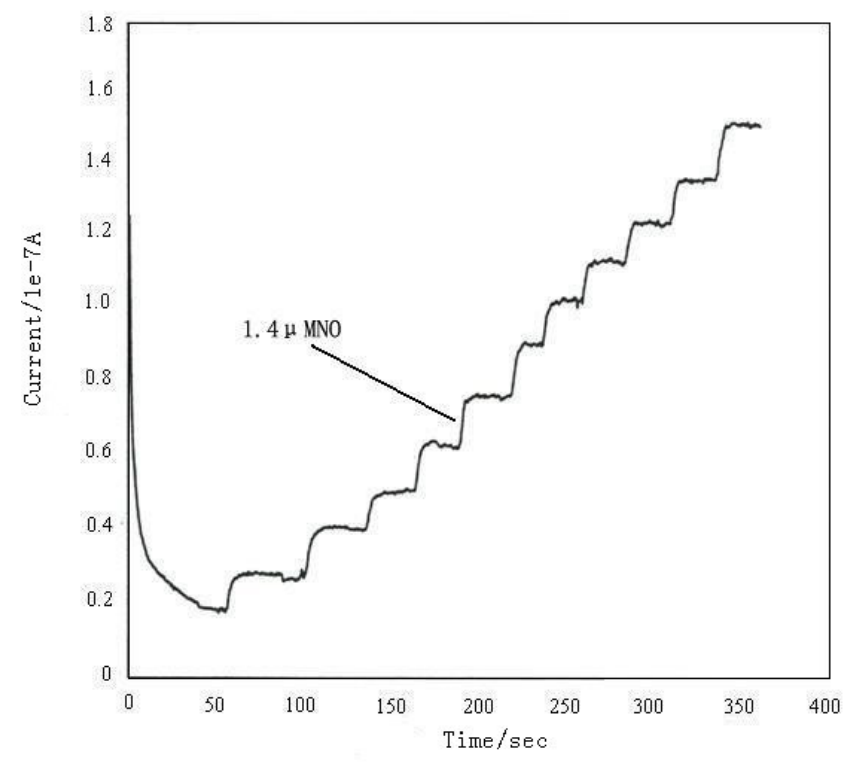

Fig. 1. current-time curve of the ISO-NOPMC microsensor to the successive additions of NO (each [NO] increment is $1.4 \grave{\mathrm{M}}$ ) in seawater.

Fig. 3 shows a current-time curve obtained on increasing the NO concentration in $0.14 \mu \mathrm{M}$ steps in seawater (curve a). In the curve a, NO was added 30 times, but only three steps appeared. As a result, NO concentration can be estimated semi-quantitatively.

Current-time curve $\mathrm{b}$ obtained on increasing the NO concentration in $0.014 \mu \mathrm{M}$ steps in seawater is shown in Fig.3 (curve b). Not all additions resulted in a peak, and most peaks were irregular. Although quantitative research is impossible with curve b, peak responses exist with NO addition. 


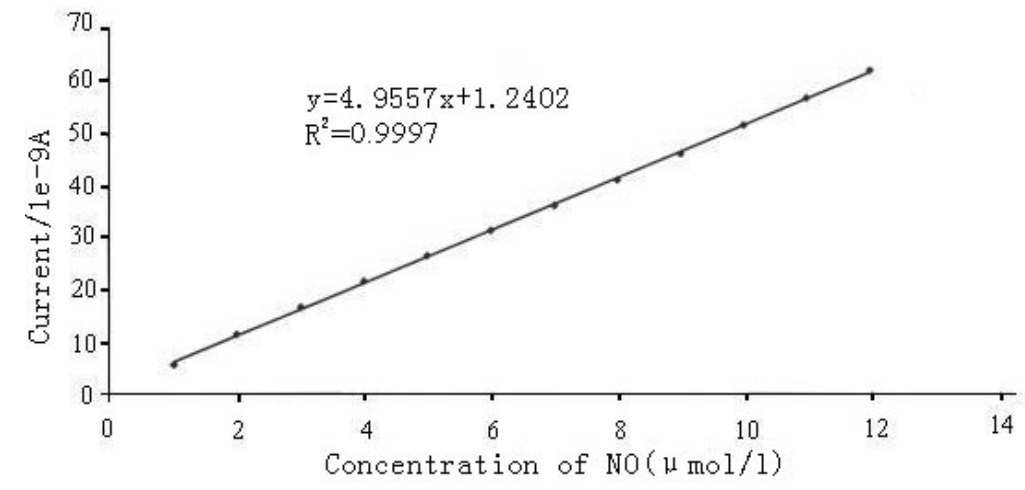

Fig. 2. Relationship between NO concentration $\bullet 10^{-6} \mathrm{~mol} / 1-10^{-5} \mathrm{~mol} / \mathrm{l} \bullet$ in seawater and electrode current measured at the ISO-NOPMC microsensor
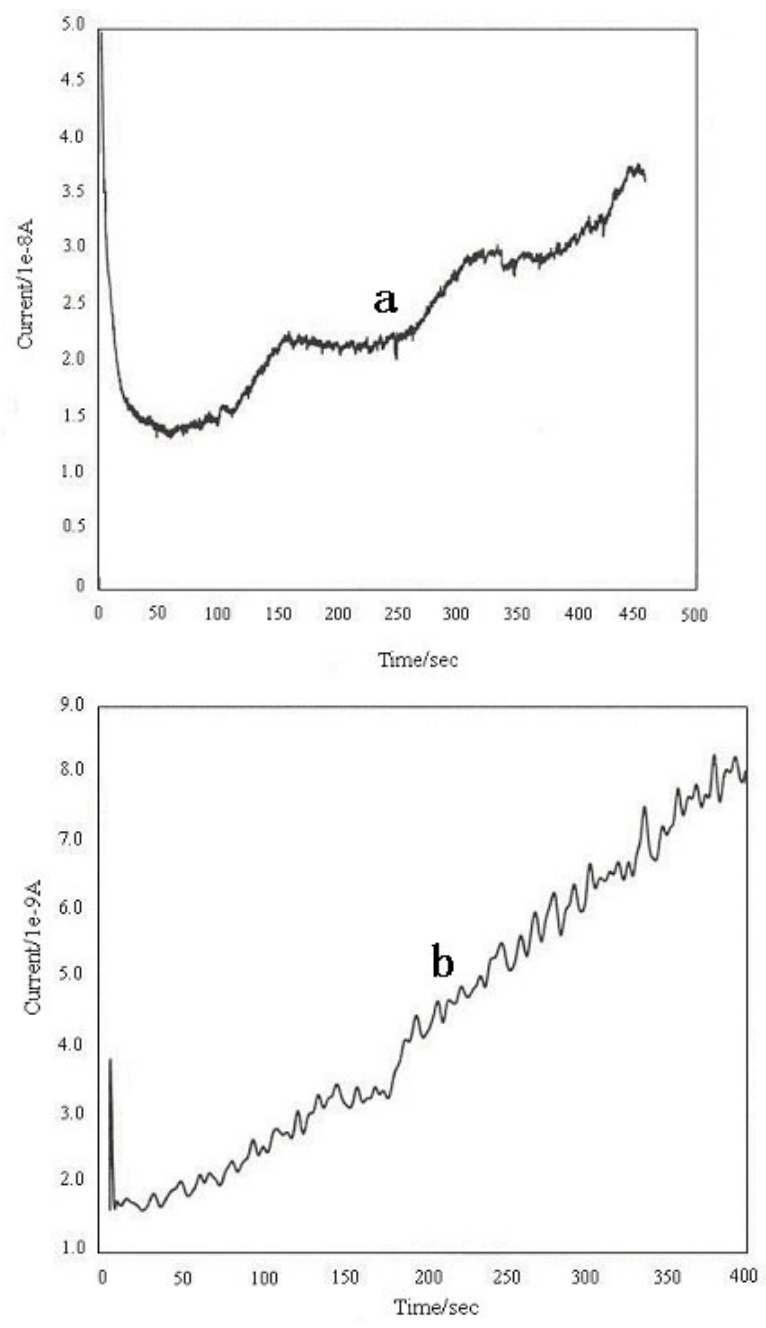

Fig. 3. current-time curve of the ISO-NOPMC microsensor to the successive additions of NO(curve a: each [NO] increment is $1.4 \times 10^{-7} \mathrm{~mol} / 1$, curve b: each [NO] increment is $1.4 \times 10^{-8} \mathrm{~mol} / \mathrm{l}$ ) in seawater. 
The lower detection limit and linear range of modified platinum microelectrode in seawater

Fig. 4 shows peak height- voltage curves of the modified platinum microelectrode to the successive additions of NO in seawater. Peaks appeared at around $0.8 \mathrm{~V}$, and peak height gradually increased with NO successive additions. The relation between the peak height and the NO concentration was linear for NO concentrations ranging from $1 \mu \mathrm{M}$ to $10 \mu \mathrm{M}$ (Fig. 5).

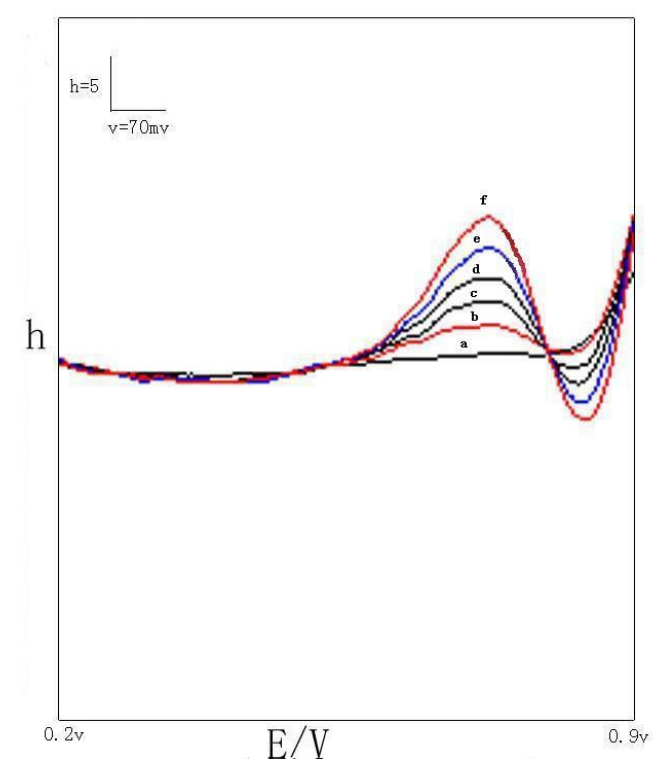

Fig. 4. Peak height- voltage curve of the modified platinum microelectrode to the successive additions of NO in seawater. Curve a, without NO; Curve b, $[\mathrm{NO}]=1.05 \bullet \mathrm{mol} / \mathrm{l}$; Curve c:[NO]=2.1 • mol/1; Curve d: $[\mathrm{NO}]=3.15 \bullet \mathrm{mol} / \mathrm{l}$; Curve e: $[\mathrm{NO}]=4.2 \bullet \mathrm{mol} / \mathrm{l}$; Curve $\mathrm{f}:[\mathrm{NO}]=5.25 \bullet \mathrm{mol} / \mathrm{l}$.

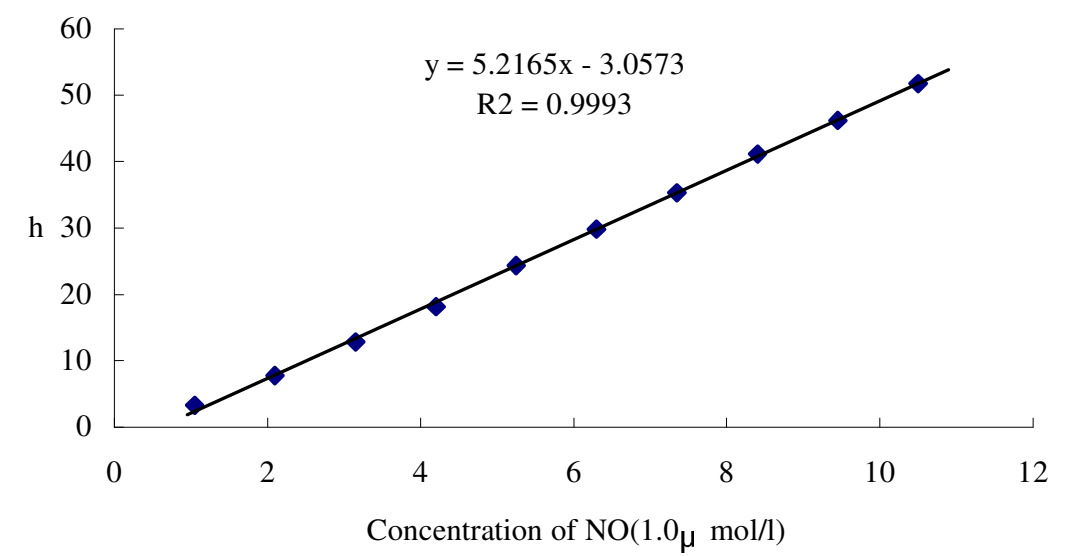

Fig. 5. Relationship between NO concentration $\bullet 10^{-6} \mathrm{~mol} / \mathrm{l}-10^{-5} \mathrm{~mol} / \mathrm{l} \bullet$ in seawater and electrode current measured at the modified platinum microelectrode

The responses of the modified platinum microelectrode to lower $[\mathrm{NO}](<0.1 \mu \mathrm{M})$ were not obvious and peak height had not clear changes with NO addition. 
The life time of ISO-NOPMC and modified platinum microelectrode in seawater

ISO-NOPMC is covered with a special selective film on its silicon chip, which is suitable to measure NO in biological media[19,20,27,28]. The film performance may degrade in seawater because the

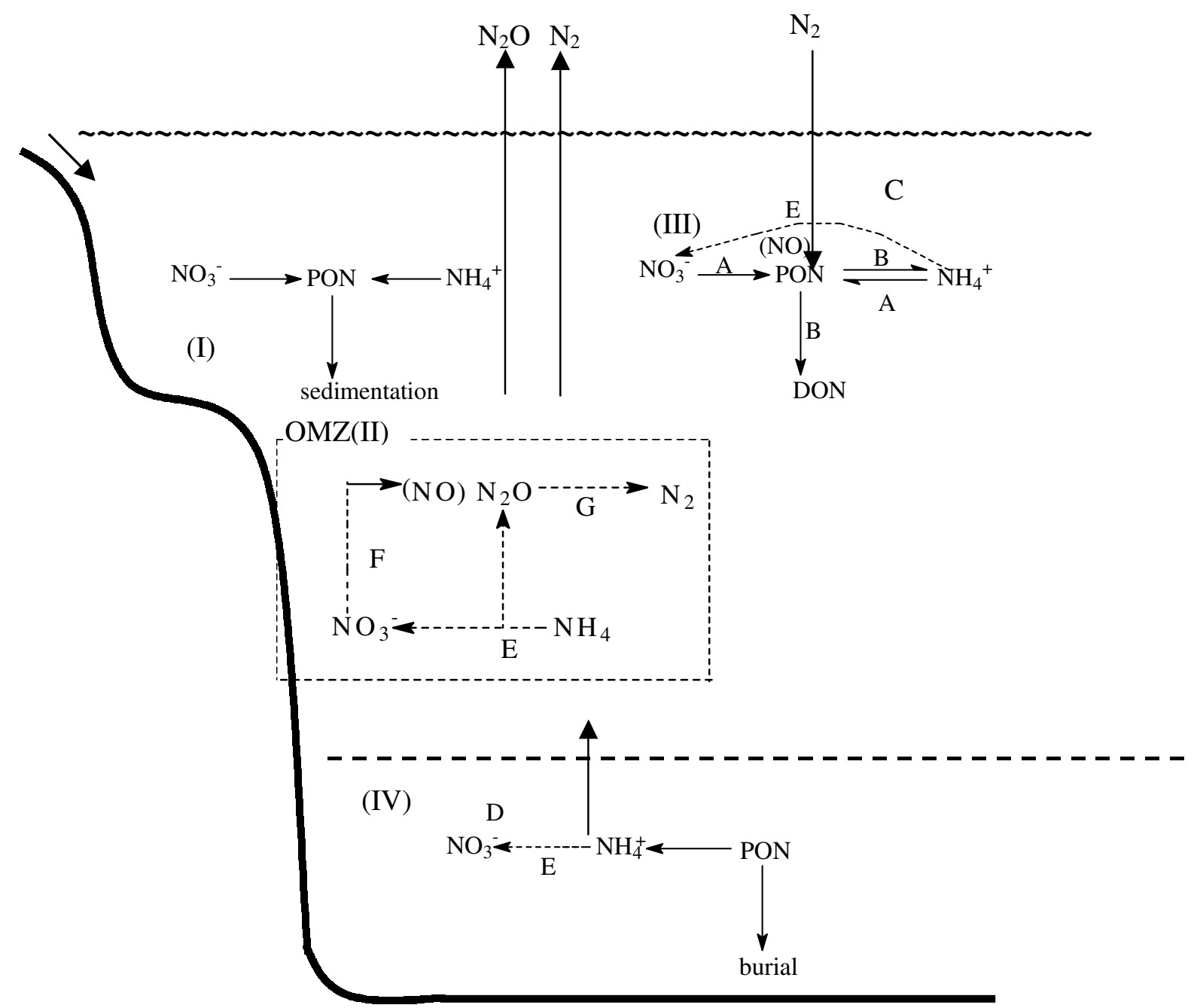

Fig. 6. Conceptual diagram of major features of the nitrogen cycle in coastal shelf and upwelling ( I ) ,OMZ (II), surface waters of the open ocean (III), and deepwater(IV). PON, particulate organic nitrogen. Dashed lines indicate transformations involving multiple steps. Pathways: A, DIN assimilation; B, ammonium regeneration; $C$, nitrogen fixation; $D$, nitrate diffusion/advection from deep water; E, nitrification; F, nitrification; G, denitrification.

composition of seawater is complex with a lot of organic substances and colloid particles. At present modified microelectrodes are generally coated by transitional metal-porphyrin, metal-phthalocyanine 
or metal-schiff base films to give rise to the electrocatalytic oxidation of NO. These compounds have a selective effect on the detection of NO.

The performance of the ISO-NOPMC microsensor used for about two months in seawater showed observable degradation. The performance of the modified platinum microelectrode used for about two days in seawater decreased obviously. The response to NO was not apparent, and no clear peak appeared at $\sim 0.8 \mathrm{~V}$.

\section{Comparison between the two methods for calibration of NO sensor}

Comparison between NO standards diluted from saturated NO solutions and decomposition of SNAP to release of NO in the presence of $\mathrm{Cu}^{+}$showed similar step height and form of current-time curves for the two methods were also similar (data not shown here). During the preparation of standard SNAP solution, more EDTA was added in the solution than that the literature [19] for the complex component of seawater.

\section{The time for exclusion of oxygen in the electrochemical cell}

The measurement of NO is difficult because of its high fugacity and low stability (its half-time is about $5 \mathrm{~s}$ in atmosphere, and is about $3 \mathrm{~h}$ in oxygen-saturated aqueous medium[21]). In fact, NO reacts rapidly with $\mathrm{O}_{2}$ to form $\mathrm{NO}_{2}{ }^{-}$and $\mathrm{NO}_{3}{ }^{-}$. Therefore, before the measurement of $\mathrm{NO}$ the electrochemical cell needs to be bubbled with nitrogen gas to remove the oxygen. The electrochemical cell with $10 \mathrm{~mL}$ seawater was respectively bubbled with nitrogen gas for 5, 10, 15, 20, 25, 30, 35, $40 \mathrm{~min}$, then $0.2 \mathrm{~mL}$ NO saturated solution was added respectively. The concentration of NO was monitored by using the HY-1CZ polarograph connected with a modified platinum microelectrode. The results show that the response current of NO increases with the $\mathrm{N}_{2}$ bubble time until $25 \mathrm{~min}$. Accordingly, time of exclusion of oxygen by bubbling with nitrogen gas should be $30 \mathrm{~min}$.

\section{Nitric oxide at ocean nitrogen cycle}

For nitrogen cycle, NO is ignored for low concentration[29] by ocean biogeochemists. However, recent chemical and biological research about nitrogen cycle[6] indicated NO perhaps was produced owing to oxygen deficiency in deep ocean or at sea surface where a lot of phytoplankton (algae) grow. Therefore NO is a possible information factor which can influence the growth of phytoplankton. We propose that the effect and status of NO ought to be taken into account at nitrogen cycle in ocean ecological system as indicated in Fig.6.

\section{Conclusion}

1. From this study, it is concluded that the ISO-NOPMC microsensor connected with Model-630 Electrochemical Analyzer is suitable for the electrochemical detection of NO in seawater. The sensitivity is lower than that of ISO-NOPMC used with ISO-Mark • nitric oxide meter in nonseawater systems by ten times. As compared with the homemade modified platinum microelectrode, 
ISO-NOPMC microsensor has higher sensitivity and stability suitable for actual detection NO in seawater.

2. The ISO-NOPMC microsensor used for about two months in seawater shows performance degradation.

3. The results of the two methods for calibration of NO sensor are consistent.

\section{Acknowledgements}

This research was supported by the National Natural Science Foundation of China (No. 40076020)• National Basic Research Priorities Programme (973)—China Ecology and Oceanology of Harmful Algal Blooms and the research fund for the doctoral program for higher education. We thank Dr. Xueji Zhang of WPI for his support of this work.

\section{References}

1. Furchgott, R.F.; Zawadzki, J.V. Nature. 1980, 288, 373 376.

2. Furchgott, R.F. Circulation Res. 1983, 53, 557 573.

3. Palmer, R.M.; Ferrige, A.G.; Moncada. Nature. 1987, 327, 524.

4. Ignarro, L.L.; Buga, G. M.; Wood, K.S.; Chaudhuri, G. Proc Natl Acad Sci. 1987, 48, 9265.

5. Koshland, D.E. Science. 1992, 258, 1861 1864.

6. Ward, B.B.; Zafiriou, O.C. Deep Sea Research. 1988, 35[7], 1127-1142.

7. Archer, S.J. FASEB. 1993, 7, 349.

8. Wallace, J.L.; Woodma R.C. Method. 1995, 7, 55.

9. Mordvintcev, P.; Mulsch, A.; Busse, R.; Vanin, A. Anal. Biochem. 1991, 199, 142.

10. Kikuchi, K.; Nagano, T.; Hiroshi, H.; Hirata, Y.; Hirobe, M. Anal. Chem.1993, 65, 1794.

11. Robinson, J.K.; Bollinger, M.J.; Briks, J.W.; Anal. Chim. 1999, 71, 5131.

12. Schulz, C.; Volker, S.; Heinge, J.; Stricher, W. Appl. Opt. 1997, 36, 3227.

13. Bedioui, F.; Trevin, S; Devynck, J. Electroanalysis. 1996, 8[12], 1085-1091.

14. Bedioui, F.; Trevin, S.; Albin, V..Anal. Chim. Acta. 1997, 341[2-3], 177-185.

15. Trevin, S.; Bedioui F.; Devynck J. J. Electroanalytical Chemistry. 1996, 408, 261-265.

16. Jin, J.Y.; Miwa, T.; Mao, L.; Tu, H. Talanta. 1999, 48, 1005-1011.

17. He, X.C.; Deng, R.; Li, P.; Mo, J.Y. J. Instrumental Analysis. 2000, 19[23], 5-38.

18. Mao, L.Q.; Lian H.T.; Tian, Y. J. Analytical Science. 1998, 14[4], 273-277.

19. Zhang, X.J.; Cardosa, L.; Broderick, M.; Fein, H.; Davies, I.R.; Electroanalysis. 2000,12[6], 425428.

20. ISO-NOPMC Nitric oxide microchip sensor, Instruction Manual, World Precision Instruments, Inc., 2002.

21. Lantoine, J.; Trevin, S.; Bedioui, F.; Devynck, J. J. Electroanal. Chem. 1995, 392, 85-86.

22. Zhao, P.Q.; Chen, S.; Deng, Y.; Mo, J.H.; Lu, T.Z.; Cai P.X. J. Instrumental Analysis. 2001, 20[3], 9-11.

23. Gerrard, W. Gas Adubilities Widespread Applications. Perggamon, Oxford, 1980.

24. Xuan, Y.Z.; Ying X.Y.; Zhang, W.; Luo, B.; Jin, L.T. Chemical Journal of Chinese University. 
1998, 19[6], 866-870.

25. McAninly, J..M.; Williams, D.L.H.; Askew, S.C.; Butler, A.R.; Russell, C. J.Chem. Soe., Chem. Commun. 1993, 1758.

26. Lange's Handbook of Chemistry, $15^{\text {th }}$ ed, McGraw-Hill, New York 1999.

27. Zhang, X.J.; Lin, J.; Cardoso, L.; Broderick, M.; Marley-Usmar, V. Electroanalysis. 2002, 14 [10], 97-103.

28. Zhang, X.J. US patent, applied No. 09/546,488, 2000.

29. Millero, F.J. Chemical Oceanography, $2^{\text {nd }}$ ed., CRC press, Boca Raton, FL 1966, pp.178. $\left(\mathrm{NO}+\mathrm{NO}_{2}: 10^{-12} \sim 10^{-8}\right.$ )

Sample Availability: Available from the authors.

(C) 2003 by MDPI (http://www.mdpi.org). Reproduction is permitted for noncommercial purposes. 